\title{
The relationships between leukotoxin production, growth rate and the bicarbonate concentration in a toxin- production-variable strain of Actinobacillus actinomycetemcomitans
}

\author{
Hiroyuki Ohta, Atsushi Miyagi, Keijiro Kato and Kazuhiro Fukui
}

Author for correspondence: Hiroyuki Ohta. Tel: +81862237151 ext. 5251. Fax: +81862224572.

e-mail: hohta@dent.okayama-u.ac.jp

Department of

Microbiology, Okayama

University Dental School,

Shikata-cho 2-chome,

Okayama 700, Japan
Actinobacillus actinomycetemcomitans, a Gram-negative periodontopathic bacterium, produces a leukotoxin belonging to the RTX family. The production of leukotoxin varies greatly among different strains of this species. In this paper the effects of growth rate and bicarbonate on the leukotoxin production by a toxin-production-variable strain (301-b) during growth in a chemostat were examined. When the bacterium was grown in anaerobic fructose-limited chemostat cultures ( $\mathrm{pH} 7.0$ and $37^{\circ} \mathrm{C}$ ) at dilution rates $(D)$ ranging from 0.04 to $0.20 \mathrm{~h}^{-1}$ in the absence and presence of $10 \mathrm{mM}$ bicarbonate, it produced leukotoxin as a cluster of two polypeptides $\left(M_{r} 113000\right.$ and 120000) and complexed with nucleic acids on the bacterial cell surface. The relationship between leukotoxin production and specific growth rate was analysed by plotting the specific rate of leukotoxin production $\left[q_{L r}\right.$, in $\mu g(\mathbf{m g} \text { dry } w t)^{-1}$ $h^{-1}$ ] against $D$. The plots were approximated to the linear relationships $q_{L T}=$ $2.7 D-0.058$ and $q_{L T}=9.3 D-0.407$ without and with bicarbonate, respectively. These relationships suggest that the apparent leukotoxin production is a result of both growth-rate-dependent production and growth-rate-independent decomposition. The cellular leukotoxin level was also followed after the change from chemostat to batch culture in the same fermenter. In batch culture leukotoxin production stopped immediately and the cellular toxin level rapidly decreased, suggesting toxin decomposition. From the slopes of the approximated linear relationships between $q_{\mathrm{LT}}$ and $D$, a theoretical maximum leukotoxin yield $\left(Y_{L T}\right)$ was estimated as 2.7 and $9.3 \mu \mathrm{g}(\mathrm{mg} \text { dry } w)^{-1}$ in the absence and presence of $10 \mathrm{mM}$ bicarbonate, respectively. The increased $Y_{\mathrm{LT}}$ value in the cultures containing bicarbonate indicated that the addition stimulated the efficiency of leukotoxin synthesis up to about threefold. Further increases of bicarbonate concentration to between 20 and $40 \mathrm{mM}$ had no effect on the total leukotoxin production, but the amount of extracellular leukotoxin increased with higher bicarbonate concentrations.

Keywords: Actinobacillus actinomycetemcomitans, leukotoxin, chemostat culture, bicarbonate effect

\section{INTRODUCTION}

Actinobacillus actinomycetemcomitans is a non-enteric, Gram-

The JIPID (International Protein Information Database in Japan) accession numbers for the $\mathrm{N}$-terminal amino acid sequences of the $M_{\mathrm{r}} 120000$ and 113000 leukotoxins are PH0266 and PH0267, respectively. negative, non-motile, facultatively anaerobic bacterium which is associated with progressive periodontal disease in children, adolescents and adults (Zambon, 1985; Slots \& Schonfeld, 1991). A major virulence factor in the pathogenicity of this bacterium is its ability to produce a polypeptide cytotoxin $\left(M_{\mathrm{r}} 113000-125000\right)$ capable of killing specifically human polymorphonuclear leukocytes 
and monocytes (Tsai et al., 1979, 1984; DiRienzo et al., 1985; Ohta et al., 1991). Molecular genetic studies have indicated that the $A$. actinomycetemcomitans cytotoxin (leukotoxin) belongs to the group of RTX cytotoxins that are characterized by the presence of a repeat domain in the C-terminal half of the proteins and by a genetic organization consisting of four contiguous genes designated $\operatorname{lt} x C, \operatorname{lt} \times A, \operatorname{lt} \times B$ and $l t \times D . \operatorname{lt} \times A$ is the toxin structural gene and $\operatorname{lt} x C$ is involved in the activation of $l+x A$ product, whereas $l+x B$ and $l+x D$ encode a secretion function (Lally et al., 1989; Strathdee \& Low, 1989; Guthmiller et al., 1990a, b; Kraig et al., 1990).

Although the ltx operon appears to be present in all $A$. actinomycetemcomitans strains (Poulsen et al., 1994), the level of toxin expression varies considerably between different strains. Analysis of several non-leukotoxic strains (e.g. ATCC 33384) showed that they possessed the ltx genes but contained low steady-state levels of $l t x \mathrm{mRNAs}$ relative to a highly leukotoxic strain JP2 (Spitznagel et al., 1991). Recently, the ltx promoters of JP2 and a minimally toxic strain (652) of $A$.actinomycetemcomitans were analysed by Brogan et al. (1994). The nucleotide sequence of the 652 promoter was similar to that of the JP2 promoter but contained a region of $530 \mathrm{bp}$ that was not present in JP2. Analysis of 15 additional strains of $A$. actinomycetemcomitans has indicated that high levels of leukotoxin expression correlate with the presence of the JP2-like promoter. However, we found that ATCC 33384 (NCTC 9710 ), containing the 652 -like promoter, produced a significant amount of leukotoxin when it was grown in a fructose-limited chemostat culture (Ohta et al., 1993). Therefore, not only the promoter structure but also some physiological factors must be involved in the regulation of leukotoxin expression.

Spitznagel et al. (1991) reported that the highly toxic $A$. actinomycetemcomitans JP2 produced high levels of toxin activity during the mid- to late-exponential phase of growth and then production decreased dramatically in the stationary phase. Growth phase-dependence was also reported in the expression of Escherichia coli haemolysin, a prototype of the RTX cytotoxins (Nicaud et al., 1985). Generally, in batch culture, the processes of growth cause the environment to change progressively and the organisms adapt continuously to these changes. Accordingly, probable environmental changes such as exhaustion of growth substrate, the accumulation of fermentation products, and environmental acidification, all may be factors leading to the cessation of toxin expression. Alternatively, the regulation of leukotoxin expression may be controlled primarily by the growth rate of the cell. This notion is supported in part by our preliminary studies of chemostat cultures of a clinical isolate (301-b) of A. actinomycetemcomitans (Ohta et al., 1991). The cells grown at a dilution rate $(D)$ of $0 \cdot 15$ or $0 \cdot 20 \mathrm{~h}^{-1}$ possessed higher leukotoxic activity than those grown at lower rates $\left(0.05\right.$ and $\left.0.06 \mathrm{~h}^{-\mathbf{1}}\right)$.

In addition to growth rate, carbon dioxide or bicarbonate appears to be another important factor for toxin production, since the growth of the organism is stimulated by bicarbonate (Slots, 1982; Ohta et al., 1989), and it is found at high concentrations in the oral environment (Jenkins, 1978). With respect to the bicarbonate effect on the growth of $A$. actinomycetemcomitans 301-b, bicarbonate stimulates not only the efficiency of ATP formation during sugar catabolism but also the efficiency of the utilization of energy for biosynthesis (Ohta et al., 1989). In this study, we have analysed in more detail the effects of growth rate and of bicarbonate on the production of leukotoxin by $A$. actinomycetemcomitans $301-\mathrm{b}$ under controlled conditions in a chemostat.

\section{METHODS}

Bacterial strain and culture conditions. A. actinomycetemcomitans 301-b (serotype a) (Ohta et al., 1987) was used throughout this study. The growth medium was composed of $50 \mathrm{mM}$ Tris $/ \mathrm{HCl}$, various mineral salts, and $0.2 \%$ yeast extract (Difco) (Ohta et al., 1989). Fructose (quantities as indicated in Results and Discussion) was autoclaved separately and added to the medium aseptically. The organism was grown in an anaerobic chemostat system as described by Ohta et al. (1989). In brief, the system was kept under a stream $\left(200-300 \mathrm{ml} \mathrm{h}^{-1}\right)$ of $\mathrm{N}_{2}$ which was freed of traces of oxygen by passage over a gas purifying column (Gas Clean GC-RX, Nikka Seiko). The temperature of culture was set at $37^{\circ} \mathrm{C}$ and the $\mathrm{pH}$ was maintained at 7.0 with $2 \mathrm{M} \mathrm{NaOH}$ or $2 \mathrm{M} \mathrm{HCl}$. Anaerobic condition was checked by monitoring culture redox potential using a platinum electrode with an $\mathrm{Ag} / \mathrm{AgCl}$ reference cell. In this system the culture redox potential (without bicarbonate, $\mathrm{pH}$ $7 \cdot 0$ ) was maintained below $-400 \mathrm{mV}$ (Ohta et al., 1991). The $\mathrm{OD}_{660}$ (LKB Novaspec 4049 spectrophotometer) of cultures was measured in a 1-cm-light-path cuvette to determine the cell densities by the averaged coefficient of the cell dry weight at $\mathrm{OD}_{660}\left[0.852 \mathrm{mg}\right.$ dry wt cells $\left.\mathrm{ml}^{-1}\left(\mathrm{OD}_{660} \text { unit }\right)^{-1}\right]$ : the relationship is linear up to $\mathrm{OD}_{660} 0 \cdot 6$ (Ohta et al., 1989).

Extraction of leukotoxin from whole cells. As described previously (Ohta et al., 1991, 1993), the leukotoxin produced is associated with nucleic acids on the cell surface when the organism is grown in fructose-limited chemostat cultures. Therefore, the leukotoxin was extracted by incubating whole cells with nuclease. In brief, bacterial cultures removed from the chemostat were centrifuged at $10000 \mathrm{~g}$ for $10 \mathrm{~min}$ at $4{ }^{\circ} \mathrm{C}$. The cell pellets were suspended at $17 \mathrm{mg}$ dry wt cells ml $\mathrm{m}^{-1}$ in $100 \mathrm{mM}$ acetate buffer ( $\mathrm{pH} 50$ ) containing $150 \mathrm{mM} \mathrm{NaCl}$ and $5 \mathrm{mM}$ $\mathrm{MgSO}_{4} \cdot 7 \mathrm{H}_{2} \mathrm{O}$. The cell suspensions were incubated with a mixture of DNase I $\left(100 \mathrm{U} \mathrm{ml}^{-1}\right)$ (Sigma) and RNase A (0.1 mg $\mathrm{ml}^{-1}$ ) (Sigma) at $25^{\circ} \mathrm{C}$ for $30 \mathrm{~min}$. After centrifugation at $10000 \mathrm{~g}$ for $10 \mathrm{~min}$, the supernatant (nuclease digest) containing the toxin was collected.

Recovery of leukotoxin from culture supernatants. The culture supernatants resulting from the centrifugation of bacterial cultures were passed through filters (pore size $0.22 \mu \mathrm{m}$ ). The filtrate was dialysed against deionized water, lyophilized and dissolved in distilled water $(1 / 20$ th of the original culture volume). The leukotoxin was detected by immunoblotting with an anti-leukotoxin serum prepared previously (Ohta et al., 1991).

SDSPAGE and immunoblotting. SDS-PAGE was performed with $7.5 \%(\mathrm{w} / \mathrm{v})$ acrylamide gels essentially as described by Laemmli (1970). Each sample (11 $\mu$ l) from the nuclease digests, concentrated culture supernatants, or whole-cell suspensions $\left(3.4 \mathrm{mg}\right.$ dry wt cells $\left.\mathrm{ml}^{-1}\right)$ was mixed with $9 \mu \mathrm{l}$ SDS-containing sample buffer and boiled for $3 \mathrm{~min}$. Proteins on the gel were visualized by silver staining with a commercial kit (Daiichi). The $M_{\mathrm{r}}$ of the leukotoxin was determined by comparison with 
known standards. Immunoblotting was carried out by the methanol/Tris/glycine method (Towbin et al., 1979). Reactivity with the anti-leukotoxin serum was detected with swine antirabbit immunoglobulin $\mathrm{G}$ conjugated to peroxidase and then visualized by adding 4-methoxy-1-naphthol and hydrogen peroxide. Leukotoxin in the samples was quantified by densitometric analysis of the SDS-polyacrylamide gel using a Beckman DU-8 spectrophotometer installed with a Beckman slab gel scanning system at a wavelength of $660 \mathrm{~nm}\left(A_{660}\right)$. To construct a standard curve of leukotoxin concentration, serial dilutions of the purified leukotoxin $\left(0-100 \mu \mathrm{g} \mathrm{ml}^{-1}\right.$ ) (Ohta et al., 1991) were processed essentially as above and analysed together with the samples on the same gel. The relationship between leukotoxin concentration and the $A_{660}$ value was linear up to $A_{660} 0.6$. The amount of leukotoxin produced was expressed in $\mu \mathrm{g}(\mathrm{mg} \text { dry wt cells })^{-1}$.

Decomposition of leukotoxin in resting cell suspension. A batch culture $(100 \mathrm{ml}$ medium with $10 \mathrm{mM}$ fructose) was incubated at $37^{\circ} \mathrm{C}$ in an anaerobic glove box (Anaerobox ANX1, Hirasawa Works) filled with $80 \%$ (v/v) $\mathrm{N}_{2}, 10 \%$ (v/v) $\mathrm{H}_{2}$ and $10 \%(\mathrm{v} / \mathrm{v}) \mathrm{CO}_{2}$. At the mid-exponential growth phase bacterial cells were collected by centrifugation at $10000 \mathrm{~g}$ for 10 min at $4{ }^{\circ} \mathrm{C}$, washed once with the growth medium without fructose and suspended in the fructose-free growth medium. The cell suspensions $\left(29 \mathrm{mg} \mathrm{dry} \mathrm{wt} \mathrm{ml}^{-1}\right)$ were incubated at $37^{\circ} \mathrm{C}$ for $16.5 \mathrm{~h}$ without and with the purified leukotoxin $\left(110 \mu \mathrm{g} \mathrm{ml}^{-1}\right)$ in the anaerobic glove box. A leukotoxin solution without bacterial cells was incubated in the same way as a control. Aliquots of the cell suspensions were sampled at $0,4,10$ and $16.5 \mathrm{~h}$ and each of them was centrifuged at $10000 \mathrm{~g}$ for $5 \mathrm{~min}$ and the supernatant was analysed by immunoblotting as described above.

Chemical analysis. Fructose concentrations in the reservoir medium and culture supernatants were determined by using the enzyme system composed of hexokinase, glucose-6-phosphate dehydrogenase and glucose-6-phosphate isomerase (Boehringer Mannheim). Bicarbonate was determined by GLC as described previously (Ohta et al., 1989).

Protein $\mathbf{N}$-terminal analysis. The separated proteins on the SDS-polyacrylamide gel were electrophoretically transferred to a PVDF membrane by the methanol/CAPS buffer method (Matsudaira, 1987). The membrane was stained for $1 \mathrm{~min}$ with $0.1 \%$ Coomassie Blue R-250, then destained with $50 \%(\mathrm{v} / \mathrm{v})$ methanol and washed with distilled water. The band of interest was cut out with a scalpel and subjected to automated Edman degradation (Hunkapiller et al., 1983) on a Perkin Elmer (Applied Biosystems) 476A protein sequencer.

\section{RESULTS AND DISCUSSION}

\section{Leukotoxin production during growth in chemostat culture}

In general, a chemostat culture is assumed to be in a steady state after growth for a minimum of five volume changes (about seven generations) under unaltered circumstances. Therefore, to examine whether or not the leukotoxin production is stabilized after five volume changes, $A$. actinomycetemcomitans 301-b was grown in a chemostat culture over an extended period and variation in the leukotoxin production during growth was followed. The growth of 301-b in the chemostat in a medium containing less than $10 \mathrm{mM}$ fructose was limited by fructose at $D$ values between 0.04 and $0 \cdot 20 \mathrm{~h}^{-1}$ (Ohta et al., 1989). The

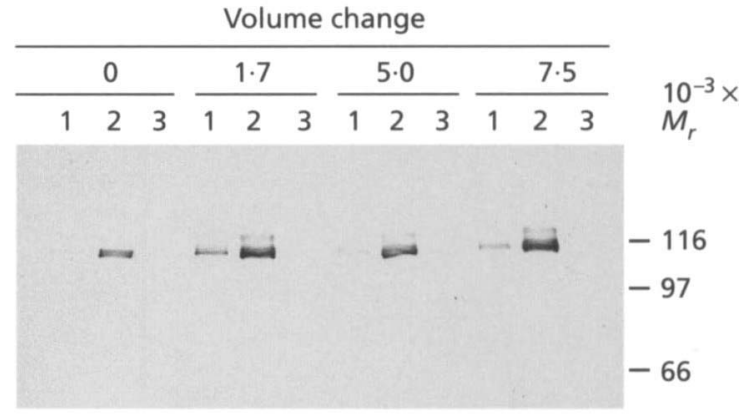

Fig. 1. Immunoblots of whole-cell suspensions, nuclease digests and concentrated culture supernatants prepared from the anaerobic fructose-limited chemostat cultures $\left(\mathrm{pH} 7.0,37^{\circ} \mathrm{C}\right)$ of $A$. actinomycetemcomitans $301-b$ after a shift from $D=0.04$ to $0.10 \mathrm{~h}^{-1}$. Culture samples were taken at $0,1.7,5.0$ and 7.5 volume changes after the shift. Lanes: 1 , whole-cell suspension; 2 , nuclease digest; 3 , concentrated culture supernatant.

initial fructose-limited chemostat culture $(7 \mathrm{mM}$ fructose in the inflowing medium) without bicarbonate was maintained at $D=0.04 \mathrm{~h}^{-1}$ for 7.6 volume changes. $D$ was then increased to $0 \cdot 10 \mathrm{~h}^{-1}$ and culture samples were taken after $1 \cdot 7,5 \cdot 0$ and $7 \cdot 5$ volume changes. Fig. 1 shows immunoblots of the whole-cell suspensions, nuclease digests and concentrated culture supernatants. The leukotoxin was found as a cluster of two polypeptides of $M_{\mathrm{r}} 113000$ and 120000 as noted by DiRienzo et al. (1985) and Lally et al. (1989). Fig. 1 also shows the association of the two polypeptides with nucleic acids on the bacterial cell surface. Namely, in any samples from the culture, the two immunoreactive polypeptides were recovered from the nuclease digest fraction (lanes 2 in Fig. 1) but not from the concentrated culture supernatants. Hence, we assumed that the measurement of leukotoxin in the nuclease digest was an accurate reflection of the cellular content of toxin. Thus, the cellular content of the $M_{\mathrm{r}} 113000\left(C_{113 \mathrm{k}}\right)$ and $120000\left(C_{120 \mathrm{k}}\right)$ polypeptides were estimated separately as described in Methods. Changes in the amount of both the peptides in the nuclease digest $\left(C_{113 \mathrm{k}}\right.$ plus $\left.C_{120 \mathrm{k}}\right)$ after the switches from $D=0 \cdot 04$ to $0 \cdot 10 \mathrm{~h}^{-1}$ and then vice versa are illustrated in Fig. 2. The cellular content of leukotoxin increased within 1.7 volume changes after the up-switch and the increased level continued until the down-switch. With the down-switch from $D=0.10$ to $0.04 \mathrm{~h}^{-1}$, the cellular content of leukotoxin decreased to a low level as in the initial culture at $D=0.04 \mathrm{~h}^{-1}$. These results indicated that the cell changed its leukotoxin production immediately in response to the shifts in $D$ and the production was regarded as being roughly stabilized after the growth for five volume changes.

\section{Effect of bicarbonate on leukotoxin production}

To examine the effect of bicarbonate on the production of leukotoxin, the inflowing medium was supplemented with sodium bicarbonate in a stepwise manner at final concentrations of $10,17,28$ and $40 \mathrm{mM}$ after a fructoselimited chemostat culture without bicarbonate had 


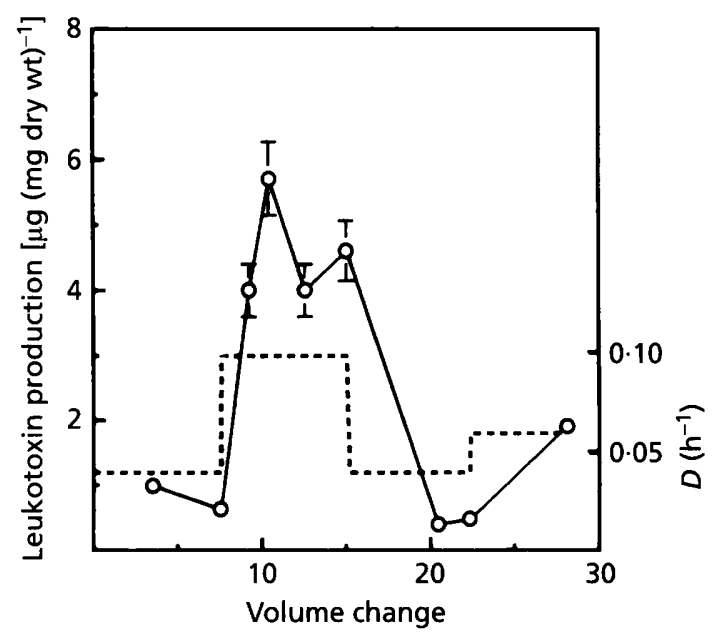

Fig. 2. Production of leukotoxin (O) by $A$. actinomycetemcomitans $301-b$ in an anaerobic fructose-limited chemostat culture $(\mathrm{pH} 7.0$, $37^{\circ} \mathrm{C}$ ) shifted from $D=0.04$ to $0.10 \mathrm{~h}^{-1}$, from $D=0.10$ to $0.04 \mathrm{~h}^{-1}$ and finally from $D=0.04$ to $0.06 \mathrm{~h}^{-1}$. The dashed line indicates changes in $D$. Error bars indicate the $90 \%$ confidence interval.

reached a steady state. A constant $D$ was maintained $\left(0 \cdot 20 \mathrm{~h}^{-1}\right)$. In these bicarbonate-added cultures the growth was still limited by fructose (Table 1). The addition of $10 \mathrm{mM}$ bicarbonate resulted in a $1 \cdot 1$-fold increase of the molar growth yield $\left.[\mathrm{g} \text { dry wt (mol fructose) })^{-1}\right]$, but a further increase of bicarbonate concentration from 10 to $40 \mathrm{mM}$ had no effect (Table 1). Fig. 3 shows immunoblots of the whole-cell suspensions, nuclease digests and concentrated culture supernatants from cells cultured with different levels of bicarbonate. Two important characteristics of leukotoxin production during growth in the presence of bicarbonate were recognized. The cellular content of leukotoxin $\left(C_{113 \mathrm{k}}\right.$ plus $\left.C_{120 \mathrm{k}}\right)$ increased with increasing bicarbonate concentration, with an apparent optimum at 10 or $17 \mathrm{mM}$ bicarbonate (lanes 2 in Fig. 3). When the bicarbonate concentration was increased to $28 \mathrm{mM}$, then to $40 \mathrm{mM}$, the leukotoxin $\left(M_{\mathrm{r}} 113000\right.$ and 120000 polypeptides) was detected in the culture supernatant fraction (lanes 3 in Fig. 3). These two characteristics

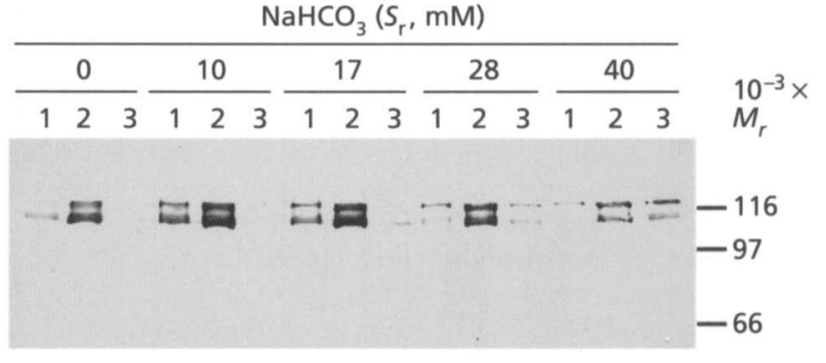

Fig. 3. Immunoblots of whole-cell suspensions, nuclease digests and concentrated culture supernatants prepared from the anaerobic fructose-limited chemostat culture $\left(D=0.20 \mathrm{~h}^{-1}, \mathrm{pH}\right.$ $7.0,37^{\circ} \mathrm{C}$ ) of $A$. actinomycetemcomitans $301-b$ in the presence of various concentrations of sodium bicarbonate. Lanes: 1 , whole-cell suspension; 2, nuclease digest; 3 , concentrated culture supernatant.

of leukotoxin production were reproducibly observed in the culture run at a lower $D\left(0 \cdot 15 \mathrm{~h}^{-1}\right)$ (data not shown).

The concentration of leukotoxin in the culture supernatant was measured by SDS-PAGE and densitometry and expressed in $\mu \mathrm{g}$ (mg dry wt cells) ${ }^{-1}\left(S_{113 \mathrm{k}}\right.$ and $\left.S_{120 \mathrm{k}}\right)$. Then, the total production of leukotoxin $\left(P_{\mathrm{LT}}\right)$ was calculated by the following equation:

$P_{\mathrm{LT}}=C_{113 \mathrm{k}}+C_{120 \mathrm{k}}+S_{113 \mathrm{k}}+S_{120 \mathrm{k}}$

Variations of these parameters by increasing the additional amount of bicarbonate are shown in Fig. 4 . The addition of 10 and $17 \mathrm{mM}$ sodium bicarbonate resulted in a $2 \cdot 5-$ to $2 \cdot 7$-fold increase in the level of cell-associated toxin $\left(C_{113 \mathrm{k}}\right.$ plus $C_{120 \mathrm{k}}$ ). This stimulation was not due to the increase of sodium ion concentration in the culture because the additions of 25 and $49 \mathrm{mM}$ sodium chloride resulted in only small increases $(1 \cdot 3$ - to $1 \cdot 5$-fold) of leukotoxin production (Fig. 4). With the further increase of bicarbonate concentration to 28 and $40 \mathrm{mM}$ the cellular toxin level decreased in a dose-dependent manner, but in compensation, the amount of extracellular toxin $\left(S_{113 \mathrm{k}}\right.$ plus $\left.S_{120 \mathrm{k}}\right)$ increased. As a result, the total production of leukotoxin was fairly constant at a bicarbonate concentration ranging from 10 to $40 \mathrm{mM}$. This indicated that

Table 1. Effect of bicarbonate on the growth of $A$. actinomycetemcomitans 301-b in anaerobic fructose-limited chemostat cultures $\left(D=0.20 \mathrm{~h}^{-1}, \mathrm{pH} 7 \cdot 0,37^{\circ} \mathrm{C}\right)$

\begin{tabular}{|c|c|c|c|c|c|}
\hline \multicolumn{2}{|c|}{ Input (mM) } & \multicolumn{2}{|c|}{ Residual (mM) } & \multirow{2}{*}{$\begin{array}{c}\text { Yield of cells } \\
\left(\mathrm{mg} \text { dry wt } \mathrm{ml}^{-1}\right)\end{array}$} & \multirow{2}{*}{$\begin{array}{c}Y_{\text {fructose }}(\mathrm{g} \text { cells } \\
\left.\mathrm{mol}^{-1}\right)\end{array}$} \\
\hline Bicarbonate & Fructose & Bicarbonate & Fructose & & \\
\hline 0 & $6 \cdot 8$ & ND & $<0.1$ & $0 \cdot 390$ & $57 \cdot 5$ \\
\hline $9 \cdot 6$ & 6.7 & 6.5 & $<0 \cdot 1$ & $0 \cdot 441$ & $65 \cdot 6$ \\
\hline $17 \cdot 2$ & 6.6 & $11 \cdot 1$ & $<0.1$ & $0 \cdot 442$ & $66 \cdot 7$ \\
\hline $28 \cdot 4$ & $7 \cdot 0$ & $19 \cdot 1$ & $<0.1$ & $0 \cdot 452$ & $64 \cdot 4$ \\
\hline $40 \cdot 4$ & $6 \cdot 8$ & $28 \cdot 6$ & $<0.1$ & $0 \cdot 443$ & $65 \cdot 1$ \\
\hline
\end{tabular}

ND, Not determined. 


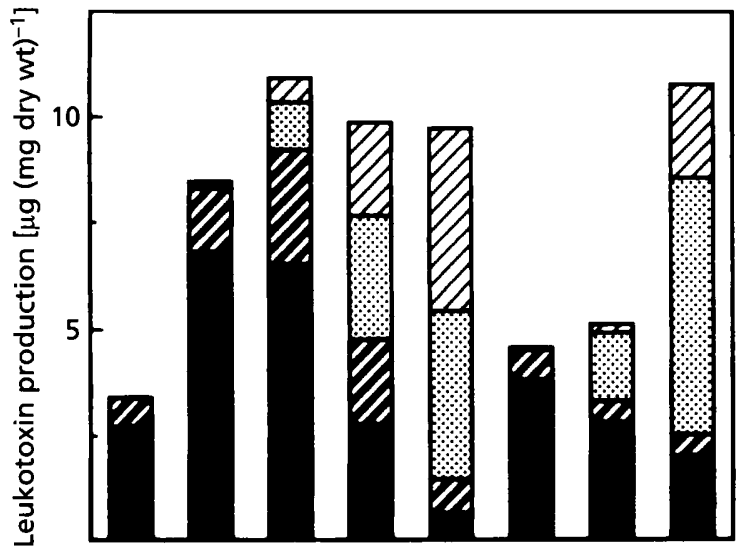

Addition of:

$\begin{array}{lrrrrrrrr}\mathrm{NaHCO}_{3}(\mathrm{mM}) & 0 & 10 & 17 & 28 & 40 & 0 & 0 & 10 \\ \mathrm{NaCl}(\mathrm{mM}) & 0 & 0 & 0 & 0 & 0 & 25 & 49 & 51\end{array}$

Fig. 4. Production of leukotoxin by $\boldsymbol{A}$. actinomycetemcomitans 301-b in anaerobic fructose-limited chemostat cultures $(D=$ $0.20 \mathrm{~h}^{-1}$, pH 7.0, $37^{\circ} \mathrm{C}$ ) with various levels of sodium bicarbonate and sodium chloride. $C_{113 \mathrm{k}}$, cellular content of $M_{\mathrm{r}}$ 113000 polypeptide $(\mathbb{\square}) ; C_{120 k}$ cellular content of $M_{r} 120000$ polypeptide $(\mathbb{Z}) ; S_{113 k}$, amount of extracellular $M_{r} 113000$

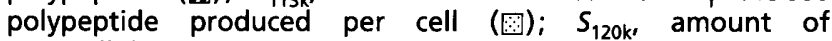
extracellular $M_{r} 120000$ polypeptide produced per cell ( $\left.\varangle\right)$.

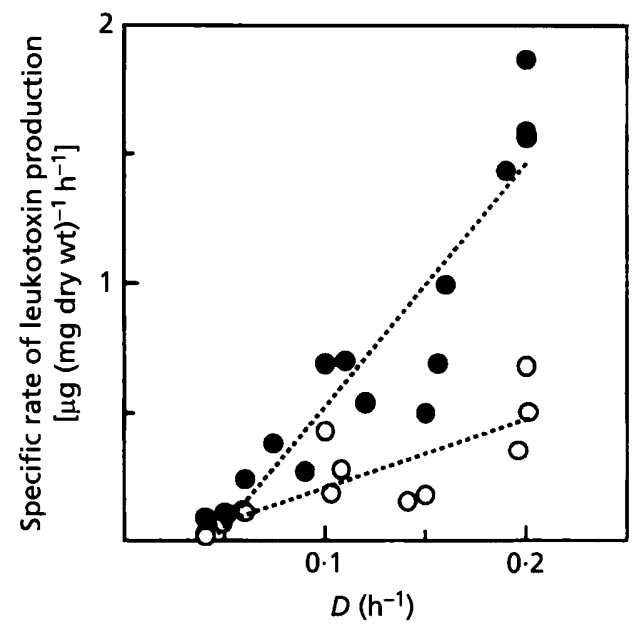

Fig. 5. Relationships between the specific rate of leukotoxin production and the specific growth rate in the anaerobic fructose-limited chemostat cultures $\left(\mathrm{pH} 7.0,37^{\circ} \mathrm{C}\right)$ of $A$. actinomycetemcomitans 301-b in the absence $(O)$ and presence (ब) of $10 \mathrm{mM}$ sodium bicarbonate. The inflowing medium contained 7 or $10 \mathrm{mM}$ fructose. The dashed lines indicate approximated linear relationships between them: $q_{L T}=2 \cdot 7 D-$ $0.058(r=0.815)$ for the cultures without bicarbonate; $q_{\mathrm{LT}}=$ $9.3 D-0.407(r=0.923)$ for the cultures with bicarbonate.

larger amounts of leukotoxin were released extracellularly into the culture fluid with higher bicarbonate concentrations. Considering the fact that the leukotoxin ( $\mathrm{pI}$ approximately 8.8 ) binds ionically to nucleic acids on the bacterial cell surface (Ohta et al., 1993), we assumed that the extracellular release was due to an increase in the ionic strength of the medium rather than the bicarbonate itself. To examine this, extra sodium chloride $(51 \mathrm{mM})$ was added to a fructose-limited chemostat culture run at $D=$ $0 \cdot 20 \mathrm{~h}^{-1}$ in the presence of $10 \mathrm{mM}$ bicarbonate and the parameters $C_{113 \mathrm{k}}, C_{120 \mathrm{k}}, S_{113 \mathrm{k}}$, and $S_{120 \mathrm{k}}$, of a steady-state culture were calculated. Under these conditions, the percentage of $S_{113 \mathrm{k}}$ plus $S_{120 \mathrm{k}}$ to $P_{\mathrm{LT}}$ increased from 2 to $77 \%$ (Fig. 4).

\section{Relation between specific growth rate and leukotoxin production}

To examine the effect of the specific growth rate on leukotoxin production, the anaerobic chemostat culture was run at various $D$ values between 0.04 and $0.20 \mathrm{~h}^{-1}$ in the absence and presence of $10 \mathrm{mM}$ bicarbonate. In each steady-state culture, the specific rate of leukotoxin production $\left[q_{\mathrm{LT}}\right.$, in $\mu \mathrm{g}$ leukotoxin (mg dry wt) $\left.{ }^{-1} \mathrm{~h}^{-1}\right]$ was calculated from the following equation:

$q_{\mathrm{LT}}=P_{\mathrm{LT}} D$

When $q_{\mathrm{LT}}$ was plotted against the corresponding $D$, the plots were approximately linear (Fig. 5). This indicated that $q_{\mathrm{LT}}$ increased with increasing specific growth rate. Assuming that the leukotoxin production is partly growth-linked and partly independent of growth rate, the relationship between $q_{\mathrm{LT}}$ and $D$ is expressed as follows (Pirt, 1975):

$q_{\mathrm{LT}}=Y_{\mathrm{LT}} D+m_{\mathrm{LT}}$

where $Y_{\mathrm{LT}}$ is the theoretical maximum leukotoxin yield referred to biomass formed $[\mu \mathrm{g}$ leukotoxin $(\mathrm{mg}$ dry $\mathrm{wt})^{-1}$ ] and $m_{\mathrm{LT}}$ is termed the maintenance rate of leukotoxin production [ $\mu \mathrm{g}$ leukotoxin $(\mathrm{mg} \text { dry wt })^{-1} \mathrm{~h}^{-1}$ ]. The plots of $q_{\mathrm{LT}}$ against $D$ in Fig. 5 can be approximated to the following equations:

for the cultures without bicarbonate,

$q_{\mathrm{LT}}=2.7 D-0.058(r=0.815)$

and for those with $10 \mathrm{mM}$ bicarbonate,

$q_{\mathrm{LT}}=9.3 D-0.407(r=0.923)$

These equations contain minus values of $m_{\mathrm{LT}}$ and therefore it can be expected that apparent leukotoxin production is a result of both growth-rate-dependent production and growth-rate-independent decomposition. Assuming the occurrence of the toxin decomposition, the 'critical' growth rate where the production rate is equal to the decomposition rate, i.e. the extrapolated intercept on the abscissa, is calculated to be 0.021 and $0.044 \mathrm{~h}^{-1}$ in the absence and the presence of bicarbonate, respectively. The $Y_{\mathrm{LT}}$ value was estimated to be 2.7 and $9.3 \mu \mathrm{g}$ leukotoxin (mg dry wt) ${ }^{-1}$ without and with bicarbonate, respectively. This parameter implies the efficiency of leukotoxin synthesis in the growing cells and thus it can be concluded that bicarbonate stimulates leukotoxin synthesis up to about threefold. Previously, we estimated several growth parameters of anaerobic fructose-limited chemostat cultures with and without bicarbonate and 


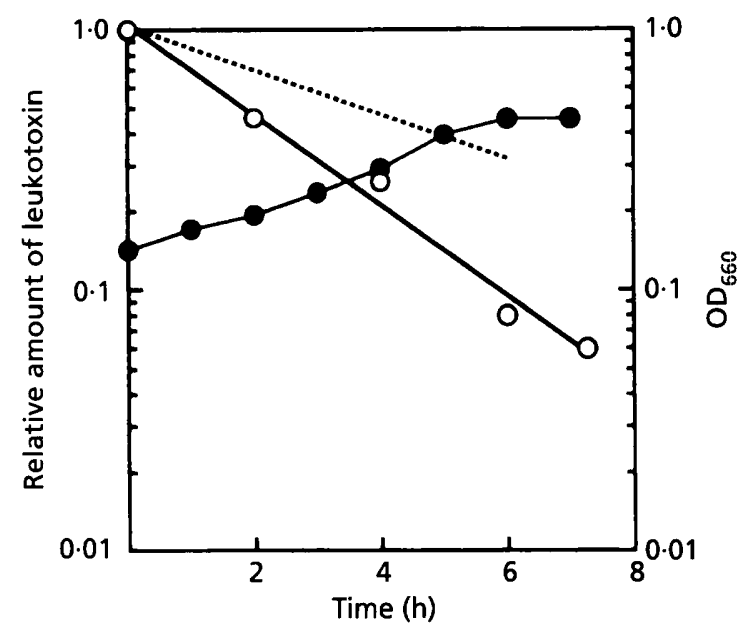

Fig. 6. Cessation of leukotoxin production induced by a growth-mode change from chemostat to batch cultures of $A$. actinomycetemcomitans $301-\mathrm{b}$. The culture was maintained at $\mathrm{pH} 7.0$ and at $37^{\circ} \mathrm{C}$ in the fructose-limited medium. $\bigcirc$, Relative amount of leukotoxin in the cells; $O, O D_{660}$. The dashed line indicates a theoretical change in the cellular leukotoxin level.

showed that the addition of bicarbonate $(48 \mathrm{mM})$ resulted in a $1 \cdot 1$-fold increase in the efficiency of ATP generation in fructose fermentation and a 1.3-fold increase of the maximum growth yield expressed as mol ATP synthesized $\left(Y_{\mathrm{ATP}}^{\max }\right)$ (Ohta et al., 1989). In general, the $Y_{\mathrm{ATP}}$ value represents the efficiency of the utilization of energy for biosynthesis. Therefore, the enhancement of leukotoxin production (about threefold increase) by bicarbonate is not simply a result of increased efficiency of total biosynthesis.

With respect to the bicarbonate effect, it was reported that the production of virulence factors by Streptococcus pyogenes and Bacillus antbracis was stimulated at the transcriptional level by bicarbonate, which was dependent on a transacting regulator (Bartkus \& Leppla, 1989; Perez-Casal et al., 1991; Caparon et al., 1992; Uchida et al., 1993; Koehler et al., 1994; Sirard et al., 1994). Such transcriptional regulation may be expected for the leukotoxin production by $A$. actinomycetemcomitans.

\section{Decomposition of leukotoxin in batch culture and resting cell suspension}

We examined the effect of a culture change from chemostat to batch on the production of leukotoxin. After a fructoselimited chemostat culture run at $D=0.10 \mathrm{~h}^{-1}$ in the presence of $10 \mathrm{mM}$ bicarbonate reached a steady state, the batch culture was begun by removing about $80 \%$ of the culture liquid from the fermenter and by immediately replacing it with the inflowing medium. The regulation of temperature, $\mathrm{pH}$ and stirring speed was the same as in the chemostat. Fig. 6 shows changes in cell density and the relative amount of cellular leukotoxin in the nuclease digest. If leukotoxin production stops immediately after

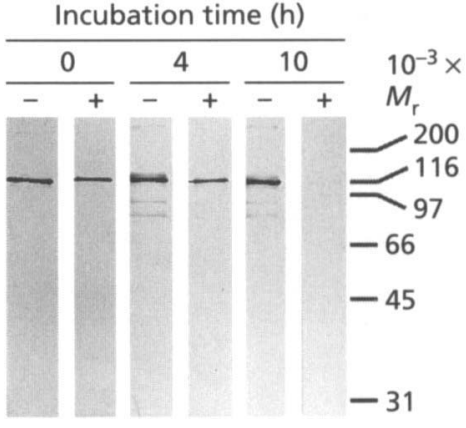

Fig. 7. Decomposition of leukotoxin by incubation in a resting cell suspension. The purified leukotoxin $\left(110 \mu \mathrm{g} \mathrm{ml}^{-1}\right)$ was incubated anaerobically at $37^{\circ} \mathrm{C}$ without (lane-) and with bacterial cells $\left(29 \mathrm{mg}\right.$ dry $\left.\mathrm{wt} \mathrm{ml}^{-1}\right)($ lane +$)$. Aliquots of the leukotoxin solution or the cell suspension were sampled after 0 , 4 and $10 \mathrm{~h}$ incubation and subjected to immunoblot analysis. For the cell suspension, the supernatant fraction was used for immunoblotting.

the growth mode change, the cellular content of leukotoxin decreases with the increase of cell mass. This theoretical change in the cellular leukotoxin level is shown also in Fig. 6 (dashed line). The actual decreasing rate of leukotoxin level $\left(-0.40 \mathrm{~h}^{-1}\right)$ was twice as high as the theoretical value $\left(-0.20 \mathrm{~h}^{-1}\right)$, suggesting that the toxin is decomposed in batch culture. During the batch culture, the leukotoxin was not detected in the culture supernatant (data not shown). The toxin decomposition was also observed when the purified toxin was incubated anaerobically in a resting cell suspension. As shown in Fig. 7, the extracellular fraction of the suspension sampled after $10 \mathrm{~h}$ incubation contained a no longer detectable amount of toxin, although the amount of toxin in the control without cells did not change significantly during $16.5 \mathrm{~h}$ incubation. In the $10 \mathrm{~h}$ incubation sample a partial cell lysis was detected by SDS-PAGE (data not shown) and therefore the leukotoxin might be decomposed by cellular protease.

\section{$\mathrm{N}$-terminal sequences of the $M_{\mathrm{r}} 113000$ and 120000 polypeptides}

To investigate the biochemical relationship between the two polypeptides, $\mathrm{N}$-terminal amino acid sequences of 26 and 25 residues were determined for the $M_{\mathrm{r}} 113000$ and 120000 polypeptides, respectively. The results are listed in Table 2 along with the corresponding sequence deduced from the DNA sequence of the $\operatorname{ltx} A$ gene of $A$. actinomycetemcomitans JP2 (Kraig et al., 1990). The Nterminal 10 amino acid sequence of the $M_{\mathrm{r}} 113000$ polypeptide was identical to the sequence between amino acid residues 16 and 25 of the $M_{\mathrm{r}} 120000$ polypeptide. This result suggests that the cleavage of the first $\mathrm{N}$ terminal 15 residues from the $M_{\mathrm{r}} 120000$ polypeptide occurs and thus yields the $M_{\mathrm{r}} 113000$ polypeptide. However, the calculated $M_{\mathrm{r}}$ (1617) of the 15 cleaved amino acid residues does not appear to compensate the difference between the apparent $M_{\mathrm{r}}$ values of both the 
Table 2. N-terminal sequences of the $A$. actinomycetemcomitans leukotoxin

\begin{tabular}{|clr|}
\hline Strain & \multicolumn{1}{c|}{ Protein } & N-terminal sequence \\
\hline JP2* & LktA & M A T T T L P N T K Q Q A A Q F A N S V A D R A K E N I D A A K E Q L Q K A L D K L \\
301-b & $M_{\mathrm{r}} 120000$ & A T T T L L N T K Q Q A A Q F A N S V A D R A E $\rightarrow$ unsequenced \\
$301-\mathrm{b}$ & $M_{\mathrm{r}} 113000$ & A N S V A D R A K E N D A A K E Q L Q K A L K L \\
\hline
\end{tabular}

* Data from Kraig et al. (1990).

polypeptides. Other unknown processing of the $M_{\mathrm{r}}$ 120000 polypeptide might occur in the formation of the $M_{\mathrm{r}} 113000$ polypeptide. One may assume that $301-\mathrm{b}$ cells contain multi copies of the leukotoxin gene. However, in our Southern blot experiments (T. Tada \& A. Miyagi, unpublished), a single hybridization signal was detected for a Sall digest of $301-b$ DNA with a $1.6 \mathrm{~kb}$ probe encoding the N-terminal half of leukotoxin. When the Nterminal 25 amino acid sequence of the $M_{\mathrm{r}} 120000$ polypeptide was compared with that of the predicted LtxA polypeptide of strain JP2, both the polypeptides were almost identical to each other except for the $\mathrm{N}$ terminal methionine residue and a proline residue at amino acid position 7 in the LtxA polypeptide.

With respect to the production of $M_{\mathrm{r}} 120000$ polypeptide, two characteristics can be noted from the present chemostat experiments. First, the relative amount of $M_{\mathrm{r}} 120000$ polypeptide increased with higher specific growth rates. For example, this is seen by comparing the amount of the polypeptide at 0 volume change $\left(D=0.04 \mathrm{~h}^{-1}\right)$ with that at 7.5 volume changes $\left(0 \cdot 10 \mathrm{~h}^{-1}\right)$ in the first experiment (Fig. 1). Second, the relative amount of the polypeptide increased in response to the increase of bicarbonate concentration in the culture (Fig. 4). In the culture at $D$ $=0.20 \mathrm{~h}^{-1}$, the percentage of $C_{120 \mathrm{k}}$ plus $S_{120 \mathrm{k}}$ to $P_{\mathrm{LT}}$ was $21 \%$ in the absence of bicarbonate, but increased to $52 \%$ with the addition of $40 \mathrm{mM}$ bicarbonate. These observations indicate that the possible processing of the $M_{\mathrm{r}}$ 120000 polypeptide is also dependent on environmental conditions.

In conclusion, we have described several characteristics of the leukotoxin production by $A$. actinomycetemcomitans 301-b. Our results show that the production is dependent on the growth rate and stimulated by bicarbonate, and also suggest the toxin decomposition in growing cells and the cessation of toxin production by the change from chemostat to batch culture. These findings will contribute to a better understanding of the in vivo pathogenesis of $A$. actinomycetemcomitans. Genetic analysis of the regulatory effects of growth rate and bicarbonate remain to be further explored.

\section{ACKNOWLEDGEMENTS}

This work was supported by Grants-in-Aid (04304044 and 06671812) for Scientific Research from the Ministry of Education, Science and Culture of Japan and by a grant from the Ryobi Foundation.

\section{REFERENCES}

Bartkus, J. M. \& Leppla, S. L. (1989). Transcriptional regulation of the protective antigen gene of Bacillus antbracis. Infect Immun 57, 2295-2300.

Brogan, J. M., Lally, E. T., Poulsen, K., Kilian, M. \& Demuth, D. R. (1994). Regulation of Actinobacillus actinomycetemcomitans leukotoxin expression: analysis of the promoter regions of leukotoxic and minimally leukotoxic strains. Infect Immun 62, 501- 508.

Caparon, M. G., Geist, R. T., Perez-Casal, J. \& Scott, J. R. (1992). Environmental regulation of virulence in group A streptococci: transcription of the gene encoding $M$ protein is stimulated by carbon dioxide. J Bacteriol 174, 5693-5701.

DiRienzo, J. M., Tsai, C.-C., Shenker, B. J., Taichman, N. S. \& Lally, E. T. (1985). Monoclonal antibodies to leukotoxin of Actinobacillus actinomycetemcomitans. Infect Immun 47, 31-36.

Guthmiller, J. M., Kolodrubetz, D., Cagle, M. P. \& Kraig, E. (1990a). Sequence of the lkt $B$ gene from Actinobacillus actinomycetemcomitans. Nucleic Acids Res 18, 5291.

Guthmiller, J. M., Kraig, E., Cagle, M.P. \& Kolodrubetz, D. (1990b). Sequence of the $1 k t D$ gene from Actinobacillus actinomycetemcomitans. Nucleic Acids Res 18, 5292.

Hunkapiller, M. W., Hewick, R. M., Dreyer, W. J. \& Hood, L. E. (1983). High-sensitivity sequencing with a gas-phase sequenator. Methods Enzymol 91, 399-413.

Jenkins, G. N. (1978). The Physiology and Biochemistry of the Mouth, 4th edn. Oxford: Blackwell Scientific Publications.

Koehler, T. M., Dai, Z. \& Kaufman-Yarbray, M. (1994). Regulation of the Bacillus antbracis protective antigen gene: $\mathrm{CO}_{2}$ and a transacting element activate transcription from one of two promoters. $J$ Bacteriol 176, 586-595.

Kraig, E., Dailey, T. \& Kolodrubetz, D. (1990). Nucleotide sequence of the leukotoxin gene from Actinobacillus actinomycetemcomitans: homology to the alpha-hemolysin/leukotoxin gene family. Infect Immun 58, 920-929.

Laemmli, U. K. (1970). Cleavage of structural proteins during the assembly of the head of bacteriophage T4. Nature 227, 680-685.

Lally, E. T., Golub, E. E., Kieba, I. R., Taichman, N. S., Rosenbloom, J., Rosenbloom, J. C., Gibson, C. W. \& Demuth, D. R. (1989). Analysis of the Actinobacillus actinomycetemcomitans leukotoxin gene. $J$ Biol Chem 264, 15451-15456.

Matsudaira, P. (1987). Sequence from picomole quantities of proteins electroblotted onto polyvinylidene difluoride membranes. $J$ Biol Chem 262, 10035-10038.

Nicaud, J.-M., Mackman, N., Gray, L. \& Holland, I. B. (1985). Regulation of haemolysin synthesis in E. coli determined by HLY genes of human origin. Mol \& Gen Genet 199, 111-116.

Ohta, H. \& Kato, K. (1991). Leukotoxic activity of Actinobacillus actinomycetemcomitans. In Periodontal Disease: Pathogens $\mathcal{E}$ Host Immune Responses, pp. 143-154. Edited by S. Hamada, S. C. Holt \& J. R. McGhee. Tokyo: Quintesence Publishing. 
Ohta, H., Kokeguchi, S., Fukui, K. \& Kato, K. (1987). Leukotoxic activity in Actinobacillus (Haemophilus) actinomycetemcomitans isolated from periodontal disease patients. Microbiol Immunol 31, 313-325.

Ohta, H., Fukui, K. \& Kato, K. (1989). Effect of bicarbonate on the growth of Actinobacillus actinomycetemcomitans in anaerobic fructoselimited chemostat cultures. J Gen Microbiol 135, 3485-3495.

Ohta, H., Kato, K., Kokeguchi, S., Hara, H., Fukui, K. \& Murayama, Y. (1991). Nuclease-sensitive binding of an Actinobacillus actinomycetemcomitans leukotoxin to the bacterial cell surface. Infect Immun 59, 4599-4605.

Ohta, H., Hara, H., Fukui, K., Kurihara, H., Murayama, Y. \& Kato, K. (1993). Association of Actinobacillus actinomycetemcomitans leukotoxin with nucleic acids on the bacterial cell surface. Infect Immun 61, 4878-4884.

Perez-Casal, J., Caparon, M. G. \& Scott, J. R. (1991). Mry, a transacting positive regulator of the $M$ protein gene of Streptococcus pyogenes with similarity to the receptor proteins of two-component regulatory systems. J Bacteriol 173, 2617-2624.

Pirt, S. J. (1975). Principles of Microbe and Cell Cultivation. London: Blackwell Scientific Publications.

Poulsen, K., Theilade, E., Lally, E. T., Demuth, D. R. \& Kilian, M. (1994). Population structure of Actinobacillus actinomycetemcomitans: a framework for studies of disease-associated properties. Microbiology 140, 2049-2060.

Sirard, J.-C., Mock, M. \& Fouet, A. (1994). The three Bacillus antbracis toxin genes are coordinately regulated by bicarbonate and temperature. J Bacteriol 176, 5188-5192.

Slots, J. (1982). Salient biochemical characters of Actinobacillus actinomycetemcomitans. Arch Microbiol 131, 60-67.

Slots, J. \& Schonfeld, S. E. (1991). Actinobacillus actinomycetemcomitans in localized juvenile periodontitis. In Periodontal Disease:
Pathogens \& Host Immune Responses, pp. 53-64. Edited by S. Hamada, S. C. Holt \& J. R. McGhee. Tokyo: Quintesence Publishing.

Spitznagel, J., Jr, Kraig, E. \& Kolodrubetz, D. (1991). Regulation of leukotoxin in leukotoxic and nonleukotoxic strains of Actinobacillus actinomycetemcomitans. Infect Immun 59, 1394-1401.

Strathdee, C. A. \& Lo, R. Y. C. (1989). Cloning, nucleotide sequence, and characterization of genes encoding the secretion function of the Pasteurella haemolytica leukotoxin determinant. $J$ Bacteriol 171, 916-928.

Towbin, H., Staehelin, T. \& Gordon, J. (1979). Electrophoretic transfer of proteins from polyacrylamide gels to nitrocellulose sheets: procedure and some applications. Proc Natl Acad Sci USA 76, 4350-4354.

Tsai, C.-C., McArthur, W. P., Baehni, P. C., Hammond, B. F. \& Taichman, N. S. (1979). Extraction and partial characterization of a leukotoxin from a plaque-derived gram-negative microorganism. Infect Immun 25, 427-439.

Tsai, C.-C., Shenker, B. J., DiRienzo, J. M., Malamud, D. \& Taichman, N. S. (1984). Extraction and isolation of a leukotoxin from Actinobacillus actinomycetemcomitans with polymyxin B. Infect Immun 43, 700-705.

Uchida, I., Hornung, J. M., Thorne, C. B., Klimpel, K. R. \& Leppla, S. H. (1993). Cloning and characterization of a gene whose product is a trans-activator of anthrax toxin synthesis. $J$ Bacteriol 175, 5329-5338.

Zambon, J. (1985). Actinobacillus actinomycetemcomitans in human periodontal disease. J Clin Periodontol 12, 1-20.

Received 16 June 1995; revised 16 October 1995; accepted 9 November 1995. 